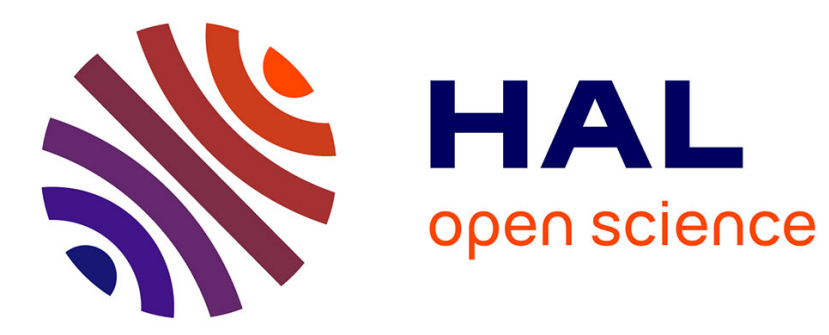

\title{
New polymer materials - new prospects
}

\author{
A. Lachinov, A. Zherebov, V. Kornilov, M. Zolotukhin
}

\section{To cite this version:}

A. Lachinov, A. Zherebov, V. Kornilov, M. Zolotukhin. New polymer materials - new prospects. Journal de Physique IV Proceedings, 1993, 03 (C7), pp.C7-1581-C7-1584. 10.1051/jp4:19937248 . jpa-00251886

\section{HAL Id: jpa-00251886 https://hal.science/jpa-00251886}

Submitted on 1 Jan 1993

HAL is a multi-disciplinary open access archive for the deposit and dissemination of scientific research documents, whether they are published or not. The documents may come from teaching and research institutions in France or abroad, or from public or private research centers.
L'archive ouverte pluridisciplinaire HAL, est destinée au dépôt et à la diffusion de documents scientifiques de niveau recherche, publiés ou non, émanant des établissements d'enseignement et de recherche français ou étrangers, des laboratoires publics ou privés. 


\title{
New polymer materials - new prospects
}

\author{
A.N. LACHINOV, A.Yu. ZHEREBOV, V.M. KORNILOV and M.G. ZOLOTUKHIN \\ Physics Department, Ufa Research Center, Academy of Sciences of Russia, K. Marx St. 6, 450000 Ufa, \\ Russia
}

\begin{abstract}
The present paper discusses experimental results obtained during the investigations of electron instabilities in the thin films of poly (3,3'-phthalidylidene-4, $4^{\prime}$-biphenyiylene) (PPB). A common feature for all these phenomena is that they are characterized by the dielectric-metal phase transition which is initiated by external effects of abnormally low values. The latter include uniaxial pressure, electric field, and temperature. Possible mechanisms of electron instabilities in thin polymer films are discussed.
\end{abstract}

\section{INTRODOCT TON}

A highly conductive state (HCS) detected recently in pristine nonconjugated polymers of the polypropylene (1) and PPB (2) types is of great interest.

Results reported in $(1,2)$ as well as in $(3,4)$ indicate that there are probably other ways avoiding doping and conjugation of valence electrons and ensureing considerably higher conductivity of organic systems. For example, in (3), the reported value of conductivity is no less than $10^{=}(\mathrm{Ohn} \mathrm{cm})^{-2}$ and in $(4)^{2}$ it is even $10^{12}\left(\mathrm{hm} \mathrm{cm}^{-2}\right.$ while the reported conductivity of doped conjugated polymers never exceeds $5 \cdot 10^{=}(\mathrm{hmm} \mathrm{cm})^{-1}$.

The nature of this abnormally high conductivity is still vague. It may result from a so-called electron switching effect (3) or occurs in cases phen the electric field of about $5-10^{2} \mathrm{~V} / \mathrm{cm}$ and the uniaxial pressure of about $10^{\circ} \mathrm{Pa}$ are applied to the polymex film simultaneously (5). Hote please the abnormally lon value of the critical pressure mhich is much lower than that measured for polyacetylene $\mathrm{P}_{\mathrm{E}}^{\sim 2} 10^{20} \mathrm{~Pa}$ (6).

In this paper re consider the possibility of inducing of HCS in thin films of non-conjugated organic polymers. 


\section{EXPERTMENTAL}

The PPB has a molecular weight of $(50-80)$-10 $0^{3}$ depending on the conditions of the synthesis. The softening temperature is $440^{\circ} \mathrm{C}$, the temperature of decomposition (TGA, $1 \%$ neight loss, air) is $450^{\circ} \mathrm{C}$. The polymer is soluble in conventional organic solvents, such as chloroform, methylenedichloride, 1,1,2,2-tetrachloroethane. The high solubility of PPBs makes it possible to purify them effectively, make films and study their various properties.

In the present rork, samples of the metal/polymer/metal sandwich type structure rere used. Polymer films less than 2000 an thick rere prepared by spin coating glass substrates with the polymer solution, whereupon a $\mathrm{Cu}$ electrode nas deposited by thermal vaporation in vacuum. Top electrodes of $\mathrm{Cu}, \mathrm{Cr}, \mathrm{Al}$, or $\mathrm{Au}$ nere deposited on the film surface in the same каy or rere pressed upon it. No effect of the electrode material on the sample properties has been detected. The samples were put into a vacuum chamber, which allowed us to perform measurements in the 77 - $430 \mathrm{~K}$ temperature range. Measurements pere performed as described in (5).

\section{RESULTS}

Electric-Field

In a high electric field (more than $10 \mathrm{~g} \mathrm{~V} / \mathrm{cm}$ ), the effect of switching rith memory was discovered in thin PPB films. In the "off" state, the polymer is a dielectric with a conductivity of less than $10^{-24}$ (Ohm $\left.\mathrm{cm}\right)^{-1}$ at room temperature and an exponential Icharacteristic. The time of spitching from the "off" to "on" state never exceeds 100 ns. In the "on" state, the I-V characteristic is ohmic, and the sample reveals metal-1ike temperature dependence of conductivity, its value at room temperature being about $1 g^{-3}(0 \mathrm{hm}$ (II) $)^{-1}$.

Dniaxial-Pressure

Fig. 1 shows current passing through the $300 \mathrm{~nm}$ thick sample as a

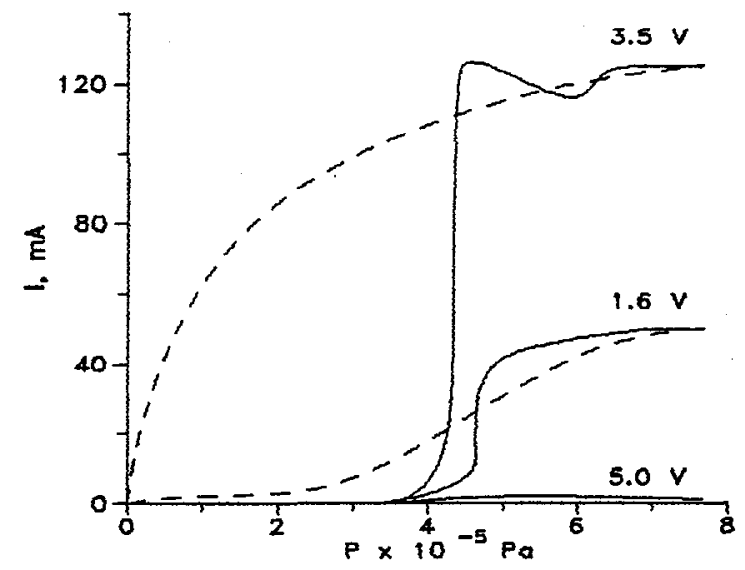

Fig. 1. Dependence of the current passing through the sample on pressure at different voltages applied to the sample. Solid curves reflect the growth of pressure and dashed curves correspond to the decrease of pressure. 
function of a uniaxial pressure $P$. Originally, the polymer film conductivity is liess than $10^{-14}$ (Ohm $\left.\mathrm{cm}\right)^{-1}$. Then the critical pressure is achieved, which is $\mathrm{P}_{c}^{\sim 5} 10^{=} \mathrm{Pa}$ in this case, conductivity abruptly increases and reaches $10^{-5}$ (Ohm $\left.\mathrm{cm}\right)^{-2}$. The phase transition induces metal-like conductivity in the polymer film. Dashed lines indicate the route of the $I(P)$ curve under the decreasing pressure. As the pressure decreases, the current often does not drop abruptly, but smoothly goes donn to zero.

Temperature

Eig.2 shops the current versus temperature plot for PPB films of different thickmesses. Measurements fere carried out during heating. Below $T_{c} 265 \mathrm{~K}$, the $\mathrm{PPB}$ is a dielectric, its conductivity being less than $10^{-12}(0 \mathrm{hm} \mathrm{cm})^{-1}$ and almost independent of the temperature. Near $T_{c}$, thermostimulated currents are observed so that in films less than 500 nm thick, a transition to a metal-like states similar to those described above occurs. The conductivity of such films rises up to $10^{-3}$ (Ohm $\mathrm{cm})^{-1}$ and its temperature dependence is metal-like type. In thicker samples, the metal-like state has never been abserved. When cooled, the metal-like state persists dom to $140 \mathrm{~K}$.

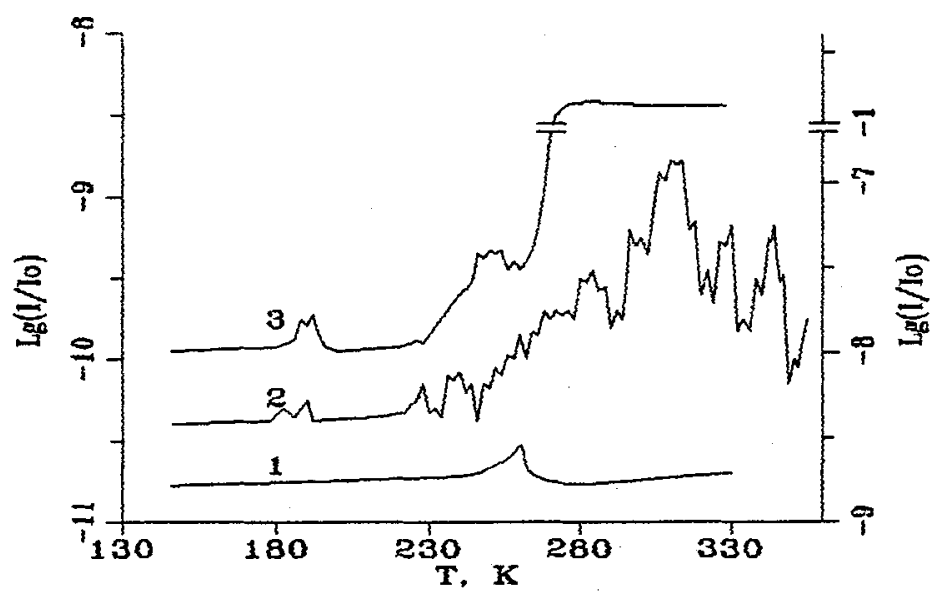

Eig. 2. Thermostimulated currents in PPB films of various thickness. Heating rate $3 \mathrm{~K} / \mathrm{min}$. Film thickness: 1 - $1900 \mathrm{~nm}$ (left axis); 2 - $1500 \mathrm{~nm}$ (right axis); $3-400$ nm (right axis).

\section{DISCOSSION}

As indicated by the experiments described above, the electric field, uniaxial pressure and heating can change the sample conductivity. All these effects induce states with similar properties so that it is impossible to define the origin of the state achieved. Let us consider some of these properties.

The "on" state possesses the anisotropy of conductivity of $\sigma_{1} / \sigma_{11}-10^{10-12}$, where $\sigma_{1}$ and $\sigma_{11}$ are conductivities across. and along time polymer film respectively. This anisotropy is due to the formation of highly conducting channels oriented across the polymer filn $\{3\}$.

In the "off" state, the conductivity of the PPB film is $a f^{s}$, where $2 \mathrm{E} z<\mathrm{f}<10>$ $\mathrm{Hz}$ is the frequency and $s \approx 1$, which confirms the hopping 
mechanism of charge transport (7). In the "on" state the sample conductipity does not depend on frequency.

The I-V characteristic of a sample in the "on" state under the bipolar santooth voltage has the shape of a symmetric "butterfly" (5).

Let us consider instabilities observed in PPB from the point of view of the polaron or bipolaron lattice theory supposed to explain the transition to the metal state in polyacetylene (8), polyaniline (9) and other polymers nith nondegenerate ground state (10). Trapping states, phose concentration in the PPB film according to the available results is sufficiently high, can form a subband in the polymer band gap. The electron-phonon interaction is very strong in such systems and hence, the charging of these states can result in the formation of polaronlike states. When their concentration is sufficiently high, the half filled polaron subband can appear. Alternatively, one of the bipolaron bands can merge with the valence or conducting bands.

In each case, the dominanting mechanism of the charge generation is probabely different. Thus, thermostimulated processes it can be ionization of specific traps. Hhen suitching is induced by the electric field, charges can be injected fron electrodes. This is incidentally confirmed by experiments on electrical luminescence (11). When uniaxial pressure is applied, changes in the surface conditions are important.

In the majority of the above mentioned cases sfitching is evidently the result of a combination of different mechanisms.

\section{REFERENCES}

[1] ENIKOLOPYAN N.S., GRIGOROV L. S., SUIRHOVA S.G., Fis'ma ZETF, 49 (1989) 326.

[2] ZHEREBOV A. YD., LACHSNOV A.N., Synt.Met, 4.4 (1991) 99.

[3] SCALDIN O.A., ZHEREBOV A. YU., LACHINOV A. N., CHOVYROV A. k., DELEY V.A., Pisma ZETE, 51 (1990) 141 .

[4] ARCHANGORODSKII V.M. GUK E.G., BLYASHEVICH A.M. , IONOV A.N., TOCHKEVICH V. S., SEL IMAK I.S., DOhladi AN SSSR, 399 (1989) 603.

[5] LACHINOV A.N., ZHEREBOV A. YO., KORNILOV V. M. , Synth. Met., 44 (1991) 111.

[6] MOSES D., EELDBLUK A., Phys.Rev. B, 26 (1982) 3363.

[7] DYRE J.C., J. Appl.Phys., 64 (1988) 2456.

[8] KIVELSON S., HEEGER A.J., Phys. Rev. Leti., 55 (1985) 308.

[9] STAFSTROM S., BREDAS J.L., EPSTEIN A.J., WOO H.S., TANNER D.B., HOANG W.S., MACDTARMID A.G., Phys. Rev. Lett., 59 (1987) 1464.

[18] CONWELL E. H. MIZES H. A., PhyS.Rev. B, 44 (1991) 937.

[11] ANTIPIN V. A., VALEEVA I. L., LACHTNOV A. N. , Pis Ma ZETE, 55 (1992) 526 . 